\title{
O CONTO NA LITERATURA ALEMÃ DO SÉCULO XX
}

\author{
Marion Fleischer
}

$\mathrm{Na}$ literatura alemã do século XX, especialmente após a Segunda Grande Guerra, o conto constitui uma forma de expressão literária intensamente cultivada, à qual já se dedicaram numerosos estudos. Colocar novamente o conto no centro da discussão seria empreendimento inócuo, se não persistissem até hoje controvérsias, cujas origens remontam a um problema básico de conceituação: o conto, tal como realizado na literatura alemã, parece subtrair-se a uma definição lapidar, sobretudo em virtude da multiplicidade de estruturas que pode exibir.

Nessa multiplicidade está centrado o presente artigo, que não pretende acrescentar nenhuma definição inaudita às muitas já existentes, mas, à semelhança do conto, apresenta um "final aberto", i.e. propõe questões para as quais inexistem respostas definitivas. Isso equivale a dizer que serão apontados alguns aspectos estruturais básicos, determinados traços formais, tendo-se em vista sempre, porém, que tais tendências são passíveis de equacionamentos os mais diversos, alguns até mesmo contraditórios.

Por essa razão Hans Bender, autor de $O$ regresso dos lobos (Die Wölfe kommen zurück), conto considerado exemplar por alguns críticos, observa em um ensaio: "O conto é o camaleão do gênero literário, um réptil sensível, que se adapta à cor de seu meio-ambiente." (1) Isto porque, ainda segundo Hans Bender, "no conto se descobrem mais características dúbias do que inequívocas. Quando afirmamos que ele geralmente oferece o recorte de uma vida mediana, imediatamente nos recordamos de exemplos contrários: contos que narram momentos culminantes da história ou de uma biografia que já conhecemos; quando afirmamos que o estilo realista é o que melhor lhe convém, eis que existem muitos exemplos de contos fantásticos, irra-

(1) - Hans Bender, Ortsbestimmung der Kurzgeschichte. In: Akzente, 3/1962, pg. 207. 
cionais ou surrealistas. Aos contos ingênuos, simples, opõem-se os contos complicados, que se aprofundam na psicologia (. ) Alguns realmente sintetizam um flagrante da vida, outros desenrolam toda uma biografia em sequências de imagens, à semelhança de um filme. Alguns concentram-se em duas pessoas que se deslocam em cenários limitados ( . . ); outros apresentam todo um universo, distribuem a ação entre figuras principais e secundárias, e abrangem a metade do globo terrestre, céu, terra e mar. Contos existem, cuja ação pode ser apresentada gráficamente com um traço linear, e outros, cuja ação se desenvolve como um meandro ou um novelo de lã, impossível de desemaranhar, ( . )"(2)

Para se avaliar quão complexo é o problema da caracterização do conto, basta folhear alguns estudos realizados a respeito do assunto:

Em seu artigo sobre "A forma curta da prosa", Walter Höllerer identifica três possibilidades de realização do conto, acrescentando significativamente, porém, que essas três modalidades representam apenas uma seleção que poderia ser complementada (3):

a) o conto-momento (Augenblickkurzgeschichte)

b) o conto-arabesco (Arabeskenkurzgeschichte)

c) o conto-surpresa (Uberdrehungskurzgeschichte) ou contomontagem (Úberblendungskurzgeschichte)

Entre os contos-momento, W Höllerer inclui, por exemplo, $O$ relógio de cozinha (Die Küchenuhr, de Wolfgang Borchert), ressaltando que a história se apóia em um único momento, em um único objeto, e em uma única palavra nesse momento, ou seja, na palavra paraiso. Mas, eis que logo em seguida se verifica existirem variações desse tipo de conto: são aqueles que reunem dois momentos relevantes, como em $O$ hóspede, de Ruth Rehmann; sim, e ocorre ainda outra variação desse modelo: o conto que reune vários momentos, ou aquele que somente flui em direção a determinado momento após uma fase introdutória. Isso por si deve ser suficiente para demonstrar a precariedade de tais subdivisões, e tornar desnecessária a descrição dos demais grupos sugeridos pelo autor, apenas aduzidos, aliás, a título de ilustração. Entretanto, seria possível argumentar que o estudo de Höllerer, publicado em 1962, já está ultrapassado. Mas mesmo a consulta de estudos mais recentes prova que os analistas

(2) - idem, ibidem, pgs. 206-207.

(3) - Walter Höllerer, Die kurze Form der Prosa. In: Akzente, 3/1962. pg. 239 e seg. 
ainda se debatem com a natureza polimórfica do conto. Veja-se por exemplo o trabalho de Klaus Doderer sobre $O$ Conto na Alemanha, de 1969: o autor distingue entre contos de ação e contos de atitude, de acordo com a ênfase dada pelos contistas ora ao desenrolar dos acontecimentos, ora às reações dos figurantes perante determinado acontecimento. Mas logo o próprio Doderer ressalta que "no caso de muitos contos essa diferenciação será supérflua, uma vez que englobam ambos os tipos" (4) A tentativa de determinar tipos de contos em função de procedimentos técnicos específicos, afigura-se igualmente insatisfatória. Doderer procede à divisão entre contos do tipo esboço, contos estritamente épicos e contos objetivos (5). No primeiro caso, trata-se de obras narrativas concentradas em delinear dada situação, por detrás da qual se esboçam os contornos de determinado destino humano; os contos estritamente épicos voltam-se para assuntos relevantes e têm por escopo impelir a ação para o acontecimento decisivo; e os contos objetivos, finalmente, propõem-se a enfocar um recorte da vida mediante uma linguagem objetiva e sóbria. Mas, novamente o próprio Doderer adverte: "a tentativa de destacar três estruturas do conto no século XX daria margem a mal-entendidos, se se pretendesse isolá-las umas das outras, seja do ponto de vista histórico, seja do ponto de vista do gênero. Pelo contrário, esses diversos tipos ocorrem paralelamente, misturam-se, apresentam variantes - como por exemplo os contos de Kafka, que constituem quase parábolas ( )" (6) A mesma flexibilidade está implícita no livro de Ludwig Rohner sobre a Teoria do Conto, publicado em 1973. Detem-se esse autor na descrição pormenorizada do tempo e do desfecho no conto: o resultado é um vasto panorama de variações técnicas possíveis, a remeter-nos novamente à observação inicial, segundo a qual o conto escapa a uma definição lapidar e não permite, portanto, qualquer fixação dentro de esquemas rígidos.

Entretanto, existem sem dúvida linhas divisórias, que identificam o conto e tornam possível diferenciá-lo de outras formas da prosa curta - da novela, por exemplo. Procuraremos mostrar algumas dessas linhas, analisando o conto $A$ espessura da pele (Die Dicke der Haut), de Siegfried Lenz, escrito nos anos 50; nele reunem-se ingredientes característicos que, em seu conjunto, permitem entrever um exemplo de microestrutura, básica para muitos contos alemães após 1945 .

(4) - Klaus Doderer, Die Kurzgeschichte in Deutschland. Darmstadt 1969, pg. 47 .

(5) - idem, ibidem, pg. 80 e seg.

(6) - idem, ibidem, pg. 89. 


\section{A ESPESSURA DA PELE}

1. Brunswik havia contratado um massagista que viesse à sua casa, e ainda antes do café da manhã fui à sua residência e anunciei-me: eu já era esperado. Uma moça de rosto sofrido abriu a porta, conduziu-me por uma escada acima, conduziu-me até uma porta es-

5. treita, bateu e deixou-me entrar.

Ele estava deitado sobre um divã coberto de peles, imóvel, com braços carnudos que pendiam molemente. Brunswik estava deitado sobre o rosto. Sua carne dorsal macia brilhava suavemente à luz janela, a gordura limpa da nuca dobrava-se em sulcos pro-

10. fundos, o queixo flácido comprimia-se lateralmente para cima: a respiração era ofegante e penosa. Lá de baixo ecoou o ganido de um cão.

"Venha", disse Brunswik, "comece"

"Sim" disse eu, "imediatamente", e preparei-me para a massagem. Distribui levemente pequenas porções de creme em suas cos.

15. tas, nos quadris macios, na nuca, e toda vez ele estremecia ao toque frio do creme, sob a ligeira pressão das pontas de meus dedos.

"Logo", consolei-o, "logo terá passado"

Ele ergueu o rosto e assentiu com a cabeça, e pude ver que Brunswik era muito jovem.

20. Novamente ecoou, lá em baixo, alto e rebelde, o ganido do cão, e enquanto meus ouvidos ainda se concentravam no ganido, Brunswik disse: "Por mim o senhor pode começar"

E comecei: espalhei o creme suavemente, esfreguei-o na pele amarelada, enfiei cuidadosamnte as mãos na carne dorsal macia,

25. pressionando-a em linha reta de cima para baixo, enquanto ele suspirava baixinho e arquejava.

"E bom", suspirou ele, "isso é bom"

III

Neste momento o cão ganiu como que acometido por uma dor súbita, e eu disse: "O senhor está ouvindo isso?"

30. "Sim", disse ele, "estou"

"Parece que o cão tem alguma coisa"

"Ce:tamente", disse Brunswik, "ele tem fome. O cão está ganindo de fome, é assim mesmo toda semana. Ele vai acostumar-se".

"É seu cão?", perguntei.

35. "Sim", disse ele.

Ao lado da omoplata profundamente embutida na gordura dorsal descobri um nódulo; pousei levemente a mão, fiz pressão com a palma, empurrei o nódulo com o polegar: agora Brunswik gemia, batia com o rosto no travesseiro, mas eu não cedia. 
40. "E este o lugar", disse eu.

"Sim", disse ele, "ali no ombro"

Com a ponta dos dedos acompanhei cuidadosamente os contornos do nódulo, tamborilei levemente e tornei a fazer pressão, até Brunswik dar um pequeno grito.

45. "Chega", pediu, "não continue nesse lugar"

Sem dizer palavra passei para o outro ombro, e quando o cão lá em baixo começou a choramingar, perguntei: "O que tem o seu cão?"

"Nada" suspirou ele, "nada mesmo. - Mas faz bem a ele passar fome. Um dia e meio por semana ele precisa passar fome.

50. Um cão precisa saber de quem recebe a comida, e que a comida não é coisa para todo dia. Além disso, a fome faz bem aos cães. Quem ama o seu cão deve deixá-lo passar fome"

"Sem dúvida", disse eu "mas um dia e meio é muito tempo"

E agora eu calcava e amassava a carne flácida dos quadris,

55. rolava-a com ambas as mãos entre polegar e indicador, beliscava e puxava, e Brunswik fechava os olhos sob a dolorosa ação benfazeja. Ele estertorava baixinho, começava a infalível sensação de sono. lência irresistível: logo, pensei, logo ele vai adormecer. Eu amassava os braços moles, carnudos, alongava a pressão até o biceps -

60. ou pelo menos até o lugar onde normalmente se encontra o biceps: a boca de Biunswik emitiu um pequeno gemido de bem-estar, um desejo inarticulado de sono.

Subitamente ecoou o ganido do cão, ecoou claro e impaciente, um ganido de alegria. Brunswik ergueu a cabeça desconfiado, pos-

65. se à escuta, e quando ao ganido seguiu-se um latido excitado, ele levantou-se, deu-me sinal para ficar no meu lugar e foi até a janela. E enquanto ele estava lá parado, desconfiado, aguçando o ouvido, eu olhava para ele: as pernas brancas, sem músculos, a gordura flácida dos quadris, a nuca esbranquiçada e arqueada; 0

70. peito macio e sem pelos arfava rápidamente, os olhos pequenos moviam-se atentos dentro das pálidas protuberâncias de gordura: o latido do cão não se repetiu.

Cansado, Brunswik voltou o divã, deu uma pequena risada, jogou-se sobre a colcha de peles e acenou-me para que eu continuasse com a massagem. E enquanto eu trabalhava a sua parte

75. traseira com batidas firmes para enrijecer a carne, abriu-se a porta. A moça de rosto sofrido olhou para dentro, sem folego, com os olhos arregalados pelo medo. Interrompi as batidas e Brunswik perguntou: "O café está pronto?"

"Sim", disse a moça em voz baixa. 
80. "Vocês conseguiram tudo? Arenque defumado quente, maionese fresca?"

"Está tudo aí", disse a moça. "O arenque agora nos é mandado pelo defumadouro, todas as manhãs"

"Já estamos terminando", disse Brunswik.

"Mas o cão", disse a moça.

85. "Ele só vai comer amanhã na hora do almoço"

"Não", disse a moça, "O cão, eu acho que o cão está morendo. Alguém lhe jogou alguma coisa por cima do muro. Ele comeu e agora está deitado em baixo da amo:eira, se debatendo. Talvez lhe deram veneno, porque ele sempre gania tanto"

90. "Vou ver o que há", disse eu, "vou descer"

A moça levou-me até em baixo, mostrou-me o jardim e as amoras pretas, e sob o arbusto estava o cão. Era um cão mag:o, com manchas marrons, tranqüilo, as patas estendidas, assim estava ele deitado de lado, na grama, sob a amoreira. A boca estava li-

95. geiramente aberta, bolhas minúsculas esverdeadas, de espuma, cobriam os beiços: o cão agora já não se debatia, estava morto.

"O que devo fazer com ele?" perguntou a moça.

"Nada", disse eu.

Voltei lentamente para a casa, entrei no quarto do divã, onde

100. estavam minhas coisas. Brunswik havia desaparecido. Juntei tudo, vesti a capa, peguei minha pasta e saí para o corredor. E então abriu-se uma porta, a porta que dava para a sala de refeiçóes: Brunswik estava sentado sózinho diante de uma mesa, vestido apenas com um roupão listado, estava sentado diante do seu café, diante

105. de travessas com arenque defumado, frios, frango, toucinho fino e ovos, e enquanto pingava maionese no pão com uma colber, ele soriu para mim e chamou: "Até amanhã, até amanhã à mesma hora"

"Sim", disse eu, "sim" Mas eu sabia que estava mentindo.

Siegfried Lenz disse certa vez a respeito de Hemingway, que êste "pretendia criar emoção através da ausência de emoção, comentar através da ausência de comentários, despertar interesse através do frio distanciamento" (7). Idêntico objetivo parece determinar o conto a ser aqui examinado.

Selecionemos pormenores do texto:

de imediato ressalta a concentração insistente na descrição do físico, mais precisamente, da obesidade disforme e indolente da per-

(7) - cit. Ludwig Rohner, Theorie der Kurzgeschichte, Athenäum Verlag, 1973, pg. 245 . 
sonagem - 0 texto refere-se contínua e repetidamente a partes de seu corpo: 4 vezes às costas, 3 vezes à nuca, 3 vezes aos quadris, 2 vezes aos braços e 1 vez respectivamente ao queixo, às pernas, ao peito e à pele; todas essas referências são acompanhadas de atributos negativos que recorrem com pequenas variações: $o$ adjetivo macio reponta 4 vezes, a flacidez é ressaltada em 3 ocasiões, o predicado carnudo aparece 2 vezes; outras particularidades, igualmente negativas, são registradas: a pele amarelada, as pernas brancas, sem músculos, a nuca esbranquiçada e arqueada, o peito macio e sem pelos; rosto e olhos, em contrapartida, acham-se vinculados a qualificações inexpressivas: o rosto é jovem, os olhos são pequenos; além disso, verificam-se quatro menções à carne e quatro à gordura da nuca, das costas, dos quadris e das protuberâncias sob os olhos de Brunswik; o texto alude, ainda, por duas vezes, à sua respiração ofegante e penosa, e a impressão de uma obesidade descomunal é reforçada pela descrição da nuca que se "dobrava em sulcos profundos", ou da "omoplata profundamente embutida na gordura dorsal" $\mathbf{O}$ denominador comum encontra-se nas conotações implícitas nas palavras macio e mole. Constata-se, assim, que das contínuas repetições e suas variantes resulta um enfoque impiedoso, do qual assoma o corpo disforme e enfermiço de Brunswik. Lassidão, debilidade, indolência, avitalidade e - detalhe importante - hipersensibilidade física caracterizam o exterior repugnante da personagem.

E como se afigura o retrato psíquico de Brunswik? Nenhuma informação explícita é fornecida ao leitor. O texto limita-se a relatar determinadas atitudes ou reações da personagem, sem comentálas ou elucidar as causas. Após rápida introdução, na qual se esboça a vida confortável de Brunswik (notem-se os sinais: massagista em casa, empregada, aos quais se acrescenta logo depois o divã coberto de peles), e se antecipa vagamente a atmosfera reinante na casa da personagem, como que resumida no "rosto sofrido" da moça que recebe o massagista-narrador, desenvolve-se o conto por seis etapas interligadas; estas sucedem-se ao longo de duas linhas paralelas de ação, e enfocam as atitudes do protagonista em face dos acontecimentos:

Na primeira etapa, ouve-se o ganido de um cão, seguido da ordem de Brunswik: "Venha, comece" Para o leitor, o ganido do cão, bem como a indiferença de Brunswik, por ora nada têm de incomum.

No segundo estágio cGnfigura-se uma situação quase paralela à primeira, acrescida, porém, de pormenores importantes: o cão gane pela segunda vez, mas agora "alto e rebelde"; assim como o narrador, também o leitor começa a prestar atenção no ganido, mas seguem-se as palavras de Brunswik: "Por mim o senhor pode começar"; já nes- 
sa fase é assinalada a sensibilidade física do paciente, que, no correr do conto, constituirá significativo elemento de contraste; essa etapa encerra-se com o início da massagem, "enquanto ele suspirava baixinho e arquejava";

A observação: "Neste momento o cão ganiu como que acometido por uma dor súbita" introduz a terceira fase; a partir deste instante, no mais tardar, a tensão que dominará todo o conto torna-se palpável; e gradativamente a indiferença de Brunswik assume proporções inquietantes: primeiro, em sua resposta lacônica à pergunta do massagista, depois, na explicação estranha que oferece para os ganidos e, finalmente, na inesperada e absurda revelação de seu "amor" pelo animal, de que julga dar provas, obrigando-o a passar fome durante um dia e meio por semana. Esta parte é veiculada por intermédio de um diálogo suscinto, mas altamente revelador da mente e do caráter da personagem. Acompanhando o diálogo, prossegue a massagem, e somamse referências ao corpo de Brunswik, ao sofrimento causado pelo tratamento e ao seu grito de dor que, secundando o ganido de dor do cão faminto, mostra num relance as causas diametralmente opostas.

$\mathrm{Na}$ quarta etapa ouve-se novamente o cão, cujo ganido é agora "claro e impaciente"; a reação de Brunswik é de desconfiança, levando-o até a janela, de onde provávelmente procura certificar-se de que a excitação do cão não se deve a algum alimento que lhe tenha sido oferecido. Neste momento, o narrador vê Brunswik de corpo inteiro à sua frente, e a descrição de sua aparência repulsiva amplią-se através do acréscimo de novos pormenores. A cena conclui com o súbito silêncio do animal: "O latido alegre não se repetiu."

No quinto estágio, a personagem central entrega-se novamente à massagem, interrompida pelo aparecimento da moça de "rosto sofrido", que comunica estar tudo preparado para o café da manhã - opulento, de acôrdo com as exigências do patrão. Neste contexto a moça dá a notícia do provável envenenamento do cão: torna-se evidente agora que seu latido alegre fôra motivado pela expectativa de receber alimento; igualmente esclarecido está o seu repentino silêncio. A reação de Brunswik consiste em não reagir e nada dizer Quem age é o narrador, que decide verificar o acontecido.

$\mathrm{Na}$ última fase do conto, o narrador constata a morte do cão, envenenado por alguém que se cansara de ouvir seus ganidos famintos; e, no final, a objetiva do narrador incide uma vez mais sobre a figura de Brunswik que, indiferente a tudo, se dispõe a saciar o seu apetite voraz diante da mesa repleta de iguarias.

Notáveis são os contrastes que conferem ao conto as suas arestas cortantes: 
1 - o cão deve passar fome para aprender a dar valor à comida; seu dono é óbviamente um glutão.

2 - Brunswik chama o massagista, a fim de minorar seus sofrimentos - resultantes de sua obesidade indolente; caracteriza-o uma extrema sensibilidade física. Este mesmo Brunswik é totalmente insensível aos sofrimentos que inflige ao seu cão faminto. 3 - a gordura descomunal de Brunswik; a magreza do cão, expressamente mencionada no fim do texto.

4 - a morte do animal por envenenamento; o apetite voraz de seu dono inabalável e sorridente.

Assim forma-se a "epiderme" do conto; por detrás dela tornase visível a vida psíquica da personagem, marcada por insensibilidade, indiferença ao sofrimento alheio, frieza, e perversão de sentimentos. A repugnância física de Brunswik, sua deformidade enfermiça, constituem a exteriorização visível, concreta, da deformação doentia e repulsiva de seu íntimo. A luz dessa conclusão, o título do conto torna-se ambigüo, sobretudo em sua forma original: Die Dicke der Haut, que permite associações com a palavra Dickhäuter $=$ paquiderme, e com a expressão er hat ein dickes $F$ ell $=$ ele tem couro grosso $=$ é insensível. O título refere-se, assim, não apenas à "espessura" da pele física, mas também à textura compacta da "pele" que cobre o íntimo da personagem. Seu aspecto físico e suas atitudes provocam reações negativas no leitor - mas o narrador não se permite a menor interferência emotiva: limita-se a arrolar friamente os fatos. Apenas a última oração do conto revela - indiretamente e sem quaisquer comentários - sua postura de crítica e de repúdio: "Mas eu sabia que estava mentindo."

Examinemos em seguida algumas particularidades que permitem situar a presente obra de ficção na categoria dos contos.

19) Em que consiste o conto de Siegfried Lenz? - sua essência reside em uma constelação momentânea, em um flagrante sintético e crítico ao mesmo tempo. Trata-se de determinado momento na vida de um ser humano, de um momento em que essa vida é confrontada com um acontecimento; à situação assim criada, deverá a personagem reagir - ou não, como no caso de nosso conto. Essa reação, por sua vez, denuncia por si só os traços característicos de sua personalidade. Muitos contos são armados sobre essa espécie de "close-up" da vida - basta lembrar $O$ pão, de W Borchert, $A$ criança gorda de M. L. Kaschnitz, $\mathrm{Na}$ ponte, de Heinrich Böll, Eles não vêem o mármore, de E. Schnabel, ou Trens na neblina, de G. Eich, entre outros.

29) A personagem - é plasmada sem detalhes supérfluos; mas aqueles poucos pormenores sobre os quais incide o holofote do narra- 
dor, são ressaltados com tintas carregadas, em função do momento crucial e revelador que o conto se propõe a desnudar. Assim, a descrição restringe-se a contornos que o leitor deverá completar, e o resultado obtido é um tipo humano específico. No conto de S. Lenz defrontamo-nos com uma "personagem plana", que não evolui interiormente. Nem sempre, porém, os ficcionistas alemães optam por personagens estáticas. Embora obedeçam geralmente à técnica de apenas esboçar suas figuras e acentuar determinados aspectos relevantes, configuram seres que, expostos a uma situação excepcional, vivenciam o encontro consigo mesmos, descobrem sua identidade mais profunda e modificam seu relacionamento com o mundo. Exemplo notável constitui o conto Trens na neblina, de G. Eich, no qual o encontro inesperado de dois irmãos leva um deles, um marginal, a reconhecer acabrunhado que "não vale nada", abrindo-se assim as perspectivas para uma reformulação total de sua vida.

A palavra "marginal" leva a outro aspecto digno de nota: é surpreendente a quantidade de contos centrados no dia-a-dia de figuras marginalizadas, i.e., de protagonistas que vivem à margem da vida . Prisioneiros, fugitivos, crianças, jovens e velhos indefesos, existências frustradas, inválidos (de corpo ou de alma) povoam esses contos. $\mathrm{Na}$ ficção de S. Lenz detecta-se, sem dificuldade, algo que se poderia chamar de "invalidez emocional". No conto intitulado $\mathrm{Na}$ ponte, de H. Böll, trata-se de um inválido da guerra, em Olaf, de $\mathbf{H}$. Kesten, o protagonista é um jovem neurótico, para citarmos apenas dois exemplos. Desnecessário será ressaltar que contos sobre fugitivos, prisioneiros, inválidos e existências quebrantadas proliferaram após a Segunda Grande Guerra .

Finalmente, cumpre ainda mencionar o papel relevante do eunarrador, que, à semelhança do que se verifica no conto de Lenz, participa diretamente dos acontecimentos. Mas ele apenas observa e registra o que estiver ao seu redor, afastando-se decididamente do papel do narrador onisciente. Em $A$ espessura da pele, o narrador mantem-se na postura do relator aparentemente frio e distanciado. Outros contos existem, porém, nos quais o eu-narrador é atingido em cheio pelos acontecimentos, como se observa exemplarmente no conto $A$ criança gorda, de M. L. Kaschnitz.

$\left.3^{\circ}\right) A$ ação é, no conto de S. Lenz. extremamente limitada; resume-se ao trabalho da massagem, a alguns deslocamentos de Brunswik e do massagista, ao ir e vir da moça "de rosto sofrido" e à acão - invisível para o leitor - do cão e da pessoa que lhe joga o alimento envenenado. E precisamente essa quase ausência de ação que impele o conto para o seu momento culminante; este, por sua vez, não se apresenta exteriormente acentuado através de recursos narrativos especiais, pelo contrário, ocorre no mesmo nivel lingüís- 
tico frio e sóbrio, próprio das passagens precedentes. O que ressalta é o impacto provocado no íntimo do eu-narrador - impacto que, no conto de Lenz, é revelado apenas indiretamente na oração final. Em numerosos contos podem-se fazer observações análogas: não "acontece" muita coisa, e raramente verificam-se acontecimentos extraordinários, "inauditos" Porque ao conto interessa, antes de mais nada, mostrar comportamentos e atitudes humanas - de preferência no seu dia-a-dia. Por isso mesmo concentra-se o conto em momentos específicos - embora cotidianos -, sejam de crise, de desilusão (vide $O$ pão, de W Borchert), de experiências trágicas, ou de renovação interior. Toda a ação flui em direção a esse impacto, que pode ser provocado pelo destino ou pelo acaso, mas de qualquer forma resulta em uma modificação, por menor que seja.

4\%) $O$ desfecho do conto distingue-o nitidamente de outras formas da prosa curta. A última frase em $A$ espessura da pele é lapidar: "Mas eu sabia que estava mentindo." - trata-se de um desfecho aberto, na medida em que nele estão implícitas interrogações para as quais o texto não oferece respostas. Embora essa oração concisa coloque exteriormente um ponto final no episódio em si, continua pairando no ar uma dissonância, uma tensão que não se desfaz. A sensação produzida por esse tipo de desfecho foi sintetizada por Hans Erich Nossack na imagem dos anéis que continuam a ondular sobre a superfície da água, depois que a pedra atingiu o fundo (8) Além disso, o momento decisivo, a "ruptura" da qual falamos acima, deflagra-se, freqüentemente, na parte final do conto, determinando sua estrutura: toda ela é composta visando o desfecho, a descarga elétrica, ou, para nos atermos à imagem de Nossack, visando o "arremesso da pedra"

$5^{\circ}$ ) Para concluirmos esse pequeno inventário, passemos ainda em revista alguns expedientes narrativos, presentes no conto de Lenz, e recorrentes em outros exemplos da forma literária que aqui examinamos. O princípio da redução sistemática ao essencial constitui um dos aspectos proeminentes do conto de S. Lenz, resultando na limitação e unidade de tempo e espaço, na concentração em momentos significativos, na concisão do diálogo, na ausência de reflexões acerca dos acontecimentos (existem, entretanto, exemplos nos quais as reflexões se inserem nos monólogos da personagem), na renúncia a comentários elucidativos, na restrição a poucas personagens (geralmente duas ou três) Assim formam-se lacunas que atiçam a imaginação do leitor, compelindo-o a preenchê-las a partir dos dados escassos e muitas vezes vagos que o narrador lhe oferece. Também a linguagem obedece ao princípio da economia, restringindo-se ao in-

(8) - Apud Hans Bender, op. cit., pg. 206. 
dispensável, ou contentando-se em despertar associaçōes. A prosa é sobria e simples, embora se possa ocultar por detrás dessa simplicidade algum problema existencial de relevância. Em consonância com essas tendências de redução, abstração e condensação máxima, predomina o estilo assindético, que evita a criação de interligações lógicas e nivela a narração.

Como procuramos mostrar no início dessas consideraçōes, poderá o conto concretizar-se através de outras variantes - a obra de Lenz é apenas uma delas. Restringimo-nos aqui a uma única forma, procurando sublinhar algumas de suas peculiaridades. Porque para o conto é igualmente válido o que se verifica em relação à novela alemã: não há uma forma "pura", que possa servir de paradigma para todas as criações individuais. Foi dito por um crítico que não existe $a$ novela -existem apenas novelas; acrescentamos: não existe $o$ conto - existem apenas contos. E verdade que as vigas mestras são imprescindíveis - mas de que forma estas são aproveitadas na edificação da obra, isso dependerá do arquiteto e de seus objetivos. 